\title{
LANGUAGE OF RELIEF: \\ MEDICAL INTERPRETING WITHIN THE SCOPE OF THE REFUGEE CRISIS RESPONSE
}

\author{
VEDRANA ČEMERIN, MARINA ČRNKO
}

\begin{abstract}
One of the main challenges facing local authorities in the regions affected by the current refugee and migrant crisis is to properly deal with the healthcare dimension, both in terms of providing adequate healthcare to migrants and regarding public healthcare of the host country. Because the crisis involves contact between people from distant regions, speaking a wide number of different languages that may be considered rare or emerging languages in the Balkans (such as Farsi and Dari or individual dialects of Arabic and Kurdish), the role of medical interpreters is often filled by ad-hoc interpreters who are native speakers of those languages, rather than trained medical interpreters. The aim of this paper is to examine the way medical interpreting services have been provided to refugees and asylum seekers in the Republic of Croatia between the peak period of the crisis in 2015 and 2019, paying special attention to the implications of this issue for the wider public healthcare concerns. The methodology used comprises an ethnographic case study supported by the qualitative analysis of interviews with the mediators involved in medical relief efforts.
\end{abstract}

Keywords: crisis translation; medical interpreting; public healthcare; refugee healthcare; volunteer interpreting

\section{Introduction}

Due to political instability, economic uncertainties, and ongoing conflicts in parts of the Middle East, Asia, and Africa (Townsend 2015, Dragović et al. 2016), Europe has in recent years faced a large-scale and far-reaching refugee and migrant crisis. One of the most important aspects of the crisis has been the provision of medical assistance and fulfilling healthcare needs of the affected refugee population, as well as protecting the health of local native populations along the migrant routes. Since various types of infectious or communicable diseases are natural hazards abetted in certain instances by human actions or inactions (Siegel 2016: 45), the mitigation of their effects through prevention, vaccination, preparedness, improved diagnostics, and the training of response teams is of crucial importance. Likewise, humans can and do serve as disease vectors, and in cases of human migration involving one or more persons infected with an infectious or communicable 
disease that disease can infect people in the receiving location, thus potentially causing an epidemic, especially in urban centres with high population density and limited access to medical facilities (Siegel 2016: 62, 113). There is a growing body of scholarly literature regarding the issues facing medical personnel involved in the response to the migration crisis in the Mediterranean Basin, their activities in the field, as well as the integration of such response-measures into the public healthcare systems of affected countries (Escobio et al. 2015, Escobio et al. 2017, Hunter 2016, Semenza et al. 2016, Scholz 2016, Lionis et al. 2018). While the land route through the Balkans became less prominent between 2016 and 2018 after the joint EU-Turkey Statement in March 2016, its importance never dwindled away completely, resurfacing once again in 2018 with growing numbers of those attempting to cross it in their efforts to reach Western Europe.

\section{Case study: theoretical framework and methodology}

The present study is part of an ongoing research project at Croatia's University of Applied Sciences Velika Gorica, focusing on the role of language mediators in the overall migrant crisis response. The initial part of the case study encompassed the peak period of the crisis in 2015-2016 (Čemerin 2019), while the present study builds upon its results and examines the de-escalation period from 2016 to 2019, with a special emphasis on medical interpreting practices. It purports to do so by using an established (both within the scope of the extant project and in the wider academic literature on the subject, cf. Brisset et al. 2013, Tesseur 2017) ethnographic approach, involving qualitative methods such as, in our case, semi-structured interviews with five language mediators, three who participated in relief operations in the reception centres and camps and the initial case study (Čemerin 2019), and two who still provide assistance to asylum seekers. It is necessary here to clarify exactly what is meant by the term medical interpreting within the context of this study. A concept closely related to those of community interpreting, public service interpreting (PSI) and crisis interpreting, and often used to denote a subtype of community interpreting which occurs in healthcare settings (Munday 2009: 194), medical interpreting or healthcare interpreting has attracted a great deal of scholarly attention over the last few decades. Both community interpreting and medical interpreting are well-researched areas, with researchers' focus ranging from the role of the interpreter in the interactive and communicative process, to professional standards and best practices, ethnographic case studies of interpreters' work, the cognitive processing of interpreting tasks (Wadensjö 1998, Angelelli 2004, Inghilleri 2005, Brisset et al. 2013, Merlini 2015, Albl Mikasa - Hohenstein 2017) and the role of medical interpreters in the triad of doctor-interpreter-patient interaction (Davidson 2001, Flores et al. 2003, Dysart-Gale 2005, Hsieh 2007, Hsieh - Kramer 2012). At its basest level, medical interpreting can be defined as the facilitation of communication between patients and healthcare providers who do not speak a common language. Due to its very nature as a type of interpreting which occurs in a semi-formal context, frequently involving native speakers of the languages of limited diffusion, for which there is a limited number of trained professional interpreters available, it is often reliant on bilingual speakers of those languages, or non-professional interpreters (Ioannidis - Resta 2016, Resta 2017), who perform the interpreters' task 
while not necessarily considering themselves interpreters in the full sense of the word. In this regard, it is similar to crisis interpreting which is also prone to using language mediators recruited ad-hoc due to the urgency of the crisis situation, time constraints, and the challenge of quickly finding a large number of trained interpreters for the language combinations to assist in the crisis response (Federici 2016: 3). In some countries, however, "healthcare interpreting has undergone considerable professionalization, with specialized professional associations, codes of professional conduct and training programs" (Munday 2009: 194). Furthermore, recent studies have examined the use of written translations of healthcare material and community translators trained in a crisis environment in a case study of health guidelines pertaining to ebola, and they found that translation facilitates the use of health-related crisis information (O’Brien - Cadwell 2017). However, the same study pointed out that its respondents expressed preference for the use and spreading of healthcare information in the spoken medium, using interpreting (O'Brien - Cadwell 2017: 42). Both of those findings are relevant for the results of this study and shall be revisited hereafter.

\section{The migrant crisis: a two-phase phenomenon}

As stated above, the migrant crisis in Croatia can be divided into two distinct phases, the first one being the peak period between September 2015 and March 2016, and the second lasting from mid-2016 up to the time of writing this text. The first phase was a large-scale emergency requiring substantial manpower and resources. During the peak period, the Croatian Ministry of the Interior recorded a total of 658,068 migrants who passed through the territory of the Republic of Croatia (Zrinjski 2016). As Croatia has been a transit country, rather than the final destination for the incoming migrants, and since the Croatian government at the time adopted a policy of open borders, this meant receiving the migrants at border crossings, providing relief and initial medical assistance in reception centres established for that purpose, transferring them by dedicated trains and buses to temporary transit centres and winter camps, and subsequently transferring those who wished to continue their journey by buses and trains to the border with Slovenia. The entire process was sustained through the efforts of various competent governmental bodies, as well as various county hospitals and emergency medical dispensaries. In addition, a few local and international non-governmental organizations provided assistance and support through the activities of their personnel and spontaneous volunteers - these include the Croatian Red Cross, Are You Syrious, the Jesuit Refugee Service, and several international organizations involving medical personnel, such as Doctors Without Borders and Magna. The findings of the initial case study (Čemerin 2019) have shown that the solution most utilized to provide language mediation during the relief operations in 2015 and 2016 was face-to-face interpreting. This was due to a number of reasons, one of them being the sheer number of persons who needed assistance, followed by the speed in which the response occurred, time constraints, and the fact that a large number of the affected population consisted of children and adults who were either unable to read or preferred personal interaction to the emotionally distant and bureaucratic tone of the written word, which is reminiscent of the aforementioned findings by O'Brien and Cad- 
well in Kenya (2017: 42). As the initial case study determined, the interpreters were all native speakers of the relevant languages, had no professional experience with translation and interpreting, volunteered for the task and came from several backgrounds: they were either bilingual citizens of Croatia who immigrated there during their studies - some of them were medical doctors and thus well-equipped to deal with both the medical and linguistic side of the relief response - or they were granted protection or temporary residence under the Croatian asylum legislation. They worked in emergency medical care facilities in reception centres and state hospitals and were coordinated by the Croatian Red Cross (Čemerin, 2019). Despite the fact that language mediators were present at all border crossings, reception centres, and camps, one of the greatest challenges for the healthcare personnel - as had indeed been the case with all other relief organizations engaged in crisis response - was the lack of linguistic knowledge regarding Arabic, Farsi, Dari, Kurdish dialects, Urdu, Pashto etc. and the accompanying lack of interpreters for those languages (Grba-Bujević et al. 2016: 103), since the number of active language mediators was low. The original case study further elaborates the fact that language mediators involved in crisis response were thus obliged to perform all necessary mediation activities as they arose, frequently working in physically demanding conditions. Due to the limited number of language mediators and their inability to be continuously present at healthcare facilities when they were needed elsewhere, medical personnel frequently sought alternative ways to communicate with the patients, including non-verbal communication. Moreover, some of the patients were quite unwilling to be admitted for further hospitalization, as they intended to continue their journey to their ultimate destination, so formal documents were drawn up, detailing either compliance or refusal of recommended diagnostic or treatment procedure, which were then translated into relevant languages by the mediators (Grba-Bujević et al. 2016: 103). While all language mediators interviewed for the purposes of the initial study claimed that they did not encounter any difficulty in providing their services, as they were native speakers of relevant languages, there were occasional cultural points of contention. For instance, male mediators would occasionally have trouble translating vocabulary related to female genital anatomy, so the medical personnel resolved this issue by using only female mediators to be present at such procedures. It may be worth mentioning that similar issues related to the concepts of gender and bodily functions in culturally conservative communities were noted by Translators Without Borders' interpreters in Rohingya refugee camps and were resolved by conducting linguistic workshops with both mediators and members of the community, which may serve as an example of good practice (Botkin 2018: 42). When it comes to language aids, the respondents of this study claimed that pivot languages such as English, French, Arabic and similar were sometimes used to clarify certain items, but no machine translation software was utilized.

\section{The migrant crisis: subsequent developments}

After the de-escalation of the crisis in 2016, the number of refugees and migrants requiring assistance decreased, so the temporary reception centres and camps were no longer required to operate in full capacity. This alleviated pressure on the healthcare system as well. The interviews conducted during the course of the second study have further 
illuminated the following developments: in August 2016 the organization Médecins du Monde or Doctors of the World, which provides both emergency and long-term medical care to vulnerable groups and populations, signed a memorandum with the Ministry of Health and the Ministry of the Interior and its medical team has since been working with persons seeking international protection and those who have received it in several reception centres for asylum seekers. Their activities are complementary and intertwined with the activities of regular local healthcare services. Médecins du Monde have their own medical team consisting of a physician, nurse, psychologist and an interpreter. At the beginning of their operation in August 2016, they published a public job tender, seeking interpreters for Arabic, conducted job interviews, and then employed two Arabic interpreters. Both were hired due to their linguistic knowledge as native speakers and due to previous working experience in the migrant reception camps. In December 2017 the organization employed an interpreter for Farsi, who was in the process of seeking international protection and had previously worked as their volunteer for a few months. He was employed since there had been a significant increase in the Farsi-speaking refugee and migrant population. Due to a very limited number of native speakers - much less qualified translators - for Farsi in Croatia, it is still very difficult to find language mediators, so this person performs mediation services not only for Farsi, but also Pashto and Urdu when the need arises. Médecins du Monde have also created their own written and printed materials containing a small glossary with medical terminology, materials for disease prevention that can also be used by medical teams, and a short guide with a map in English, French, Arabic, and Farsi, explaining the shortest and easiest route from the Porin Reception Centre in which they operate to the nearest hospital. Disease prevention leaflets are colourful, simple, and involve reminders to properly wash hands, dispose of waste and consider the health risks of tobacco. Leaflets concerning diseases include short descriptions, symptoms and pertinent information regarding chickenpox and scabies, and have been distributed to other organizations working with the migrant population as well. They are meant to serve as basic information to acquaint their users with elementary concepts, not to replace medical consultation. The healthcare dictionary is short, contains basic vocabulary, and is in five languages: Croatian, English, French, Arabic, and Farsi. It is divided into eighteen terminological sub-fields, four of which are medically-related: body parts, health, indications (doctors' orders) and hygiene. The rest deals with feelings, thinking and behaviour, clothes and footwear, family and relationships, institutions and services, daily expressions, time, orientation, public transportation, accommodation, living space, food and drink, money, numbers, and colours.

The respondents of the second study have furthermore clarified that, in addition to medical services, the largest part of their work entails accompanying the migrants to the hospitals and medical institutions (for further testing, bloodwork, etc.). This corresponds to the activities of other non-governmental organizations engaged in aiding the refugee and migrant population, such as the Croatian Red Cross. Apart from psychotherapy, which demands a language mediator due to its sensitive nature, the role of the interpreter in a medical setting is often more related to administrative and escorting duties, rather than interpreting itself. It may even be said that serving as an escort to migrants is their primary duty. Escorting entails consultations with medical personnel regarding medical procedures to be undertaken on behalf of the patient, completing paperwork, and admin- 
istrative tasks (sight translation); reminding and informing asylum seekers of their legal rights and the way to exercise them, as well as explaining to the patients how to properly describe their ailments and physical complaints. So, they are essentially a combination of language, cultural, and legal mediators, important not only as interpreters but also as accompaniment and support. They serve as the link between the medical institution and the patient, help the patients fulfil their legal rights. This is especially relevant in light of the difference in the legal status of a person seeking international protection and the person who has been granted asylum, considering that the extant legislation divides the extent of healthcare services obtainable based on this distinction.

In addition, the respondents of the second study claimed in interviews that the mediators work as interpreters only after they enter the room where the doctor-patient interaction is taking place, where they are required to serve as interpreters only (meaning that they are not allowed to provide additional comments or explanations, only translate the words said by both the physician and the patient as they have been said). This feature is particularly pronounced when the interaction is between the patient and the psychologist, as the patients are frequently sufferers of PTSD due to traumatic experiences in their countries of origin or during their journey. A graduate thesis based on the survey conducted in July 2016 with the refugees registered in one of Zagreb reception centres for seekers of international protection found that $80.3 \%$ of examinees showed high levels of psychological distress (Stanković 2017: 30).

\section{The present study: discussion of the findings}

When asked about good practice, the respondent from Médecins du Monde claimed that it is sometimes better to allow the patient to use their own mediator during the doctor-patient interaction, usually a friend or family member chosen by the patient themselves, as opposed to using a language mediator from the organization, since the patient is more likely to trust and feel at ease with someone they know well. In such cases the language mediator from the organization is required to leave the room. Likewise, there are some patients who want to communicate with the medical personnel in English, with no assistance from the interpreter, and this is allowed if it is their own decision. The respondents claimed that it is of paramount importance to respect the decisions of the patient, whether they decline to have an interpreter or to have someone from their social circle serve as a non-professional interpreter.

When it comes to linguistic pitfalls or vocabulary issues, dialectal differences were claimed to occasionally pose a problem, but not to the extent that they would be considered a serious issue. The respondents have also claimed that - at the moment when the interviews were conducted - the greatest difficulty in providing language mediation was to find enough interpreters for Farsi, Urdu, Pashto, and the Kurdish dialects, since the number of patients who are native speakers of those languages is constantly on the rise. As of yet, there is no official and qualified court interpreter for Urdu or Pashto in the Republic of Croatia, so language mediation is still sometimes performed through pivot languages such as English, French or Farsi, which invites possible mistranslations and the accumulation of errors in the chain of communication. 
However, in terms of the interpreters' role and modality of work, an interesting development arose during the course of the interview session: when asked to point out the most important aspect of the mediators' work, all respondents claimed that it is of greatest importance to train the persons who are to be engaged as interpreters for the proper manner of performing their tasks, especially if they have no prior experience as medical interpreters. They clarified this by stating that - when working alongside the physician or the psychologist - the interpreter must translate word-for-word, by no means interpreting the meaning or adding something of their own to the utterance said. This is somewhat peculiar as most interpreters are taught to do the opposite, striving for the transfer of meaning and avoiding literal translations (e.g. Handbook for Interpreters in Asylum Procedures 2017: 52). And yet, it may also be said that this piece of advice echoes some of the guidelines listed in the Translators Without Borders' Field guide to humanitarian interpreting and cultural mediation: "Do not comment on what you interpret or answer a question on behalf of one of the speakers" (2017: 8). This issue is related to the fact that the language mediators are required to keep to their own profession and duties, in order to avoid potential interference with the provision of medical assistance. This means they are perceived in the traditional utilitarian sense of interpreter-as-conduit (Hsieh - Kramer 2012: 158), passive transmitters of others' words and an instrument in the process of doctor-patient communication with neither influence nor control over the flow of the dialogue. This firmly excludes the possibility of them taking initiative in the communicative process and filling the role of co-diagnostician (Hsieh 2007: 925). Since Flores et al. (2003) concluded in their study that $63 \%$ of the interpreting errors were found to have potential clinical consequences, it may be surmised that the aim of such restrictions is to avoid just such occurrences and their undesirable effects. This corresponds to some of the claims made by the respondents of the second study, who illustrated this point by stating that their interpreters are sometimes given discharge summary reports and other paperwork to read, but the physician has not yet completed all medical procedures or has required further testing to be done: in such cases, the interpreters are not allowed to share what they believe they know with the patients, as there is no final diagnosis yet, but it is rather a suspected diagnosis which is to be clarified further by the qualified medical professionals. The interpreters are also frequently asked by the patients whether they've seen their test results and medical paperwork, and they are taught to refer all such questions to the medical doctor, to minimize their own interference in the doctor-patient interaction. Essentially, the interpreter is not a medical professional and must never try to act as one or to assume any of the aspects pertaining to this role. This notion of an interpreter firmly established in the role of a professional language service provider, yet at the same time occupying a somewhat fluid space in terms of the socio-emotional relationship with their clients is further supported by the comments made by another respondent in the study, who when asked about their personal views and experiences with regard to their duties and the scope of their work - described several types of potential issues. The first among them were the difficulties in learning Croatian grammar, since their mother tongue was Arabic, and they believed that as an interpreter/mediator, they also needed to be able to work with Croatian, not only with the Arabic-English language pair, and their work needed to be as professional as possible. They likewise pointed out occasional ethnic tensions among the migrants of different ethnic groups (specifically, people from Afghanistan and Iran 
sometimes objected to their mediator coming from an Arabic-speaking background, even if they spoke Persian). However, by far the most important was the tendency of people to project their feelings and problems onto the mediator, blaming them for unsuccessfully resolved issues. More precisely, they rejected their assistance since the mediator's words contravened their views or wishes, even though the mediator simply cited the legislative provisions with regard to the issue at hand, rather than providing a personal opinion.

\section{Conclusion}

The main goal of the current study was to determine the role played by language mediators in the provision of medical services in the refugee context in the Republic of Croatia. It set out to do this by using an ethnographic and descriptive approach. It may be said that in this regard it has fulfilled its primary aims. However, its scope is necessarily limited and dictated by its qualitative framework and the availability of sources, especially as this particular crisis is a currently active and rapidly evolving phenomenon, markedly different from its beginnings in 2015 and continuously transforming due to new developments. The implications this has for the healthcare services in the countries on the Balkan route are evident, with a particular need to monitor the potential occurrence of communicable diseases or even outright epidemics among the migrant population, such as pediculosis and scabies. The incidence of diseases that have been suppressed in this area like tuberculosis or measles and the obligation to provide urgent medical assistance due to injuries and other medical emergencies should also be considered. It must be noted that the provision of healthcare services to migrants never interfered with the provision of healthcare services to the citizens of the Republic of Croatia, even at the peak of the crisis (Grba-Bujević et al. 2016: 100-101), and the presence of disease among the migrant population had no impact on the native Croatian population.

Likewise, despite the successful completion of the major relief operation in 2016, certain points are equally valid today as they have been at the height of the crisis: there is a lack of trained and qualified interpreters for some of the languages spoken among the migrant population, and this issue is quite difficult to resolve as those languages mostly maintain a low and sporadic presence in the Croatian language market due to the lack of their economic viability. It may be anticipated that the language mediators engaged to perform mediation in the asylum and migrant contexts will continue to be recruited from a pool of native speaker volunteers and the migrant population itself. It is thus of extreme importance that the interpreters are given clear instructions on how to perform their duties and trained to work as medical interpreters, as well as to familiarize them with all aspects of day-to-day activities of the crisis relief personnel. Likewise, as may be gleaned from the respondents involved in the present study, several items are noteworthy:

1. The mediators need to be familiar with the operating guidelines and best practices of the organization that employs them, not only in terms of language assistance but also of general activities.

2. Their duties and scope of authority need to be firmly established and defined.

3. They need to receive institutional support from their employer in terms of training and daily activities. 
In the context of any major crisis or disaster, the concepts of crisis translation and medical interpreting are impossible to neatly separate, so language mediators need to be able to work in both areas and perform their duties with speed, accuracy, and precision insomuch as they can, while keeping as close to the professional standards as may be expected in such circumstances. While the present study did not presume to provide any prescriptive advice or measures on how to realize this goal, it did note several strategies utilized by the active mediators and the humanitarian and medical personnel operating in the ongoing crisis management process. Albeit some of those strategies, such as the use of pivot interpreting or non-verbal communication, carry inherent communicative hazards and the potential to lose some of the meaning in the translation process, one should also bear in mind that crisis situations strongly differ from regular working conditions, both in terms of healthcare professions and language mediation. In translation practice, this often leads to the trade-off between precision, style, and speed. It may therefore be of use to include these strategies in the training of prospective crisis-medical interpreters, so as to mitigate their potentially adverse effects on the overall working process, and thus optimize the potential of the general crisis response.

\section{REFERENCES}

Albl Mikasa, Michaela - Hohenstein, Christiane (2017) 'Cognition in community interpreting: the influence of interpreter's knowledge of doctor-patient interaction', in Daniel Perrin - Ulla Kleinberger (eds.) Doing Applied Linguistics: Enabling Transdisciplinary Communication, Berlin: de Gruyter, 130-138.

Angelelli, Claudia V. (2004) Medical interpreting and cross-cultural communication, Cambridge: Cambridge University Press.

Botkin, Katie (August/September 2018) 'The linguistics of refugee response', Multilingual: https:// magazine.multilingual.com/previewissue/aug-sep-2018/the-linguistics-of-refugee-response (access: 10. 1. 2019).

Brisset, Camille - Leanza, Yvan - Laforest, Karine (2013) 'Working with interpreters in health care. A systematic review and a meta-ethnography of qualitative studies', Patient Education and Counseling 91(2): 131-140.

Čemerin, Vedrana (2019) 'Language Mediation in Emergency Migration Contexts: a Case Study of the Migrant Crisis 2015 in Croatia', in Christophe Declercq - Federico M. Federici (eds.) Intercultural Crisis Communication: Translation, Interpreting and Languages in Local Crises, London: Bloomsbury Academic, 39-62.

Davidson, Brad (2001) 'Questions in cross-linguistic medical encounters: The role of the hospital interpreter', Anthropological Quarterly 74(4): 170-178.

Dragović, Filip - Jure Tadić (2016) 'Migracijska i izbjeglička kriza, sigurnosni rizici za EU (Migrant and Refugee Crisis - Security risks for EU)', Policija i sigurnost 1(16): 14-41.

Dysart-Gale, Deborah (2005) 'Communication models, professionalization, and the work of medical interpreters', Health Communication 17(1): 91-103.

Escobio, Favila - Echevarria, Jota - Rubaki, Silvia - Viniczai, Virag (2015) 'Health assistance of displaced people along the Balkan route, The Lancet (386): 2475.

Escobio, Favila - Etiennoul, Maryse - Spindola, Stephany (2017) 'Rescue medical activities in the Mediterranean migrant crisis', Conflict and Health 11(3).

European Commission (2017) EU-Turkey Statement, one year on, Bruxelles: European Commission.

Federici, Federico M. (ed.) (2016) Mediating Emergencies and Conflicts - Frontline Translating and Interpreting, Basingstoke: Palgrave Macmillan. 
Flores, Glenn - Laws, Michael Barton - Mayo, Sandra J. - Zuckerman, Barry - Mesa Abreu - Milagros, Medina Leonardo - Hardt, Eric J. (2003) 'Errors in medical interpretation and their potential clinical consequences in paediatric encounter', Paediatrics 111(1): 6-14.

Translators Without Borders (2017) Field guide to humanitarian interpreting and cultural mediation, Danbury: Translators Without Borders.

Grba-Bujević, Maja - Dragosavac Maja - Janev-Holcer, Nataša - Važanić, Damir (2016) 'Response of Croatian healthcare system to migrant crisis in the period from September 16 to December 31, 2015', Liječnički Vjesnik 138(3-4): 99-103.

Hsieh, Elaine (2007) 'Interpreters as co-diagnosticians: Overlapping roles and services between providers and interpreters', Soc Sci Med. 64(4): 924-937.

Hsieh, Elaine - Kramer, Eric M. (2012) 'Medical Interpreters as Tools: Dangers and Challenges in the Utilitarian Approach to Interpreters' Roles and Functions', Patient Educ Couns 89(1): 158-162.

Hunter, Philip (2016) 'The refugee crisis challenges national health care systems: Countries accepting large numbers of refugees are struggling to meet their health care needs, which range from infectious to chronic diseases to mental illnesses', EMBO Reports 17(4): 492-495.

Inghilleri, Moira (2005) 'Mediating zones of uncertainty. Interpreter agency, the interpreting habitus and political asylum adjudication', The Translator 11(1): 69-85.

Ioannidis, Anastasios - Resta, Zoi (2016) 'Professionalization opportunities for community interpreting in Greece: a sociological approach', in 8th EST Congress 2016 Book of Abstracts, Aarhus, 215.

Lionis, Christos et al. (2018) 'Assessing refugee healthcare needs in Europe and implementing educational interventions in primary care: a focus on methods', BMC International Health and Human Rights 18(1).

Merlini, Raffaella (2015) 'Empathy: A zone of "uncertainty" in mediated healthcare practice', Cultus 8: 27-49.

Munday, Jeremy (2009) The Routledge Companion to Translation Studies, London; New York: Routledge.

O'Brien, Sharon - Cadwell, Patrick (2017) 'Translation Facilitates Comprehension of Health-Related Crisis Information: Kenya as an Example', Journal of Specialised Translation (28): 23-51.

Parliament of the Republic of Croatia. ACT ON INTERNATIONAL AND TEMPORARY PROTECTION, clean version, Official Gazette NN 70/15, 127/17.

Resta, Zoi (2017) Non-Professional Interpreting: the Greek Case: http://blog.peempip.gr/non-professional-interpreting-greek (access: 4. 6. 2018).

Scholz, Nicole (2016) The public health dimension of the European migrant crisis. European Parliament Briefing, Luxembourg: European Parliament.

Semenza, Jan C. et al (2016) 'Public health needs of migrants, refugees and asylum seekers in Europe, 2015: Infectious disease aspects', European Journal of Public Health 26(3): 372-373.

Siegel, Frederic R. (2016) Mitigation of Dangers from Natural and Anthropogenic Hazards. Prediction, Prevention and Preparedness, Basel: Springer International Publishing.

Stanković, Nikolina (2017) Sada je zapravo sve dobro ili ipak ne? Ispitivanje mentalnog zdravlja izbjeglica i migranata, Zagreb University Faculty of Humanities and Social Sciences: Department of Psychology. Unpublished Master's thesis: http://darhiv.ffzg.unizg.hr/id/eprint/8468/1/nstankovic2017.pdf (access: 25. 9. 2019).

Tesseur, Wine (2017) 'Incorporating translation into sociolinguistic research: Translation policy in an international non囚governmental organisation', Journal of Sociolinguistics 21(5): 629-649.

Townsend, Riley M. (2015) The European Migrant Crisis, Morrisville: Lulu Press, Inc.

UN High Commissioner for Refugees (UNHCR) (2017) Handbook for Interpreters in Asylum Procedures. Wadensjö, Cecilia O. (1998) Interpreting as interaction, London: Longman.

Zrinjski, Ivan (2016) 'Kako se odvijala migrantska kriza', Jutarnji list, 9. 3. 2016, https://www.jutarnji.hr.

Vedrana Čemerin, Marina Črnko

University of Applied Sciences Velika Gorica

marina.crnko@vvg.hr

vedrana.cemerin@vvg.hr 